\title{
Self e Autenticidade: Dilemas Conceituais sob a Perspectiva de Merleau-
}

\author{
Ponty \\ Gilberto Hoffmann Marcon* \\ Universidade de São Paulo - USP, Ribeirão Preto, SP, Brasil \\ ORCID: http://orcid.org/0000-0002-4589-463X \\ Reinaldo Furlan* \\ Universidade de São Paulo - USP, Ribeirão Preto, SP, Brasil \\ ORCID: http://orcid.org/0000-0003-2117-3886
}

\begin{abstract}
RESUMO
Propomos mapear as implicações do pensamento fenomenológico para as temáticas correlatas do self e da autenticidade, com ênfase na perspectiva merleau-pontyana. Perpassando as acepções distintas dos fatores identitário, unitário e relacional da experiência humana, encontramos três eixos tensionais em torno dos quais o conceito de self pode ser articulado: constância ou mudança, particularidade ou universal e pessoa ou mundo. Sob os diferentes enfoques descritivos deste campo de problemas, tais dilemas epistemológicos encontram-se redobrados em tensões éticas quando nos reportamos à questão da autenticidade. Enquanto as filosofias de Heidegger e Sartre, sob aproximações diferentes, concedem relativa centralidade à problemática da autenticidade, a fenomenologia de Merleau-Ponty, mesmo situada no diálogo direto com tais aportes de raiz comum husserliana, não concede ao tema a mesma importância de forma explícita. Ao tematizar o caráter eminentemente ambíguo da corporeidade, Merleau-Ponty oferece uma compreensão original da experiência do self e do ser autêntico: em contraponto à possibilidade radical de recuo, a inerência radical de contato. Concluímos que tal perspectiva apresenta como ganho a habilitação da apreensão descritiva, sem cair em contradição, do que há de concretude no indeterminado, de universal na singularização e de passividade na liberdade - e vice-versa, para todos os casos.
\end{abstract}

Palavras-chave: fenomenologia, autenticidade, self, identidade, Merleau-Ponty.

\section{Self and Authenticity: Conceptual Dilemmas under Merleau-Ponty's}

\section{Perspective}

\begin{abstract}
We propose to map the implications of the phenomenological thought for the correlated themes of self and authenticity, with an emphasis on the merleau-pontyan perspective. Throughout the different understandings of the identitary, unitary and relational factors of human experience, we observe three tension axes around which the concept of self can be


articulated: constancy or change, particularity or universality and person or world. Under the different descriptive approaches of this field of problems, such epistemological dilemmas are redoubled in ethical tensions when we refer to the question of authenticity. While the philosophies of Heidegger and Sartre, under different approaches, grant relative centrality to the issue of authenticity, Merleau-Ponty's phenomenology, although situated in direct dialogue with these contributions from the same Husserlian roots, does not give the theme the same explicit importance. By focusing on the eminently ambiguous character of corporeality, Merleau-Ponty offers an original understanding of the experience of the self and the authentic being: as opposed to the radical possibility of retreat, the radical inherence of contact. We conclude that such perspective presents as a gain the qualification of a descriptive apprehension, without falling into contradiction, of what there is of concreteness in the indeterminate, universal in singularization and passive in freedom - and vice versa, for all cases.

Keywords: phenomenology, authenticity, self, identity, Merleau-Ponty.

\section{Self y Autenticidad: Dilemas Conceptuales bajo la perspectiva de Merleau-}

\section{Ponty}

\section{RESUMEN}

Proponemos mapear las implicaciones del pensamiento fenomenológico para los temas correlacionados del self y de la autenticidad, con énfasis en la perspectiva merleau-pontyana. A lo largo de los diferentes entendimientos de los factores identitarios, unitarios y relacionales de la experiencia humana, encontramos tres ejes de tensión en torno a los cuales se articula el concepto de self: constancia o cambio, particularidad o universalidad y persona o mundo. Bajo los diferentes enfoques descriptivos de este campo de problemas, tales dilemas epistemológicos se redoblan en tensiones éticas cuando nos referimos a la cuestión de la autenticidad. Si bien las filosofías de Heidegger y Sartre, bajo diferentes enfoques, otorgan una relativa centralidad al tema de la autenticidad, la fenomenología de Merleau-Ponty, aunque ubicada en un diálogo directo con tales contribuciones de raíz común husserliana, no cede al tema la misma importancia de manera explícita. Al centrarse en el carácter eminentemente ambiguo de la corporeidad, Merleau-Ponty ofrece una comprensión original de la experiencia del self y del ser auténtico: en oposición a la posibilidad radical de retirada, la inherencia radical del contacto. Concluimos que dicha perspectiva presenta como ganancia la calificación de una aprehensión descriptiva, sin caer en contradicción, de lo que hay de concreto en lo indeterminado, universal en singularización y pasivo en libertad, y viceversa, para todos los casos.

Palabras clave: fenomenología, autenticidad, self, identidad, Merleau-Ponty. 
Propomos um mapeamento teórico das temáticas correlatas de self e autenticidade na interface entre a psicologia e a fenomenologia, com especial interesse pelo pensamento de Maurice Merleau-Ponty. Interlocutor frequente da psicologia de sua época, Merleau-Ponty delineia ao longo de sua obra uma noção de subjetividade corporificada a qual, através de seus desenvolvimentos e transformações, lança as bases para uma reabilitação conceitual que contempla questões epistemológicas centrais aos aportes psicológicos contemporâneos sobre tais temas. Com seu ponto de partida sendo a reconhecida insuficiência das compreensões dualistas do fenômeno humano, originárias no modo de pensar cartesiano, acreditamos que a filosofia do autor possibilita enquadrar o campo de questões relativas ao self de forma a oferecer leituras que subsidiem compreensões renovadas a respeito das diversas tensões e paradoxos que envolvem tais investigações no âmbito da ciência psicológica.

Trata-se de um campo amplo que articula conceituações fundamentais como as de identidade, individualidade e pessoalidade ${ }^{1}$, tendo com isso papel crucial na relação mutuamente determinante entre psicologia individual e social (Spink, 2011). Nesse sentido, poderia se dizer que a complexidade do conceito de self ${ }^{2}$ é coextensiva à própria ciência psicológica, uma vez que todo estudo neste campo dos saberes postula - quer de maneira explícita no trato efetivo do tema, quer por consequência implícita a construtos funcionais localizados - uma compreensão epistemológica a respeito desse aspecto da experiência humana.

A abrangência do tema é tal que sua delimitação conceitual acaba por envolver a abordagem de premissas e pressupostos às vezes tomados como evidentes no contexto de sua articulação e na construção dos objetos de estudo efetuada por cada área do saber psicológico. Assim, compreendemos que uma investigação teórica do conceito de self sob uma perspectiva fenomenológica - ou seja, preocupada sobretudo com a possibilidade metodológica de abordar tais questões sob um critério rigorosamente descritivo da experiência concreta - guarda especial interesse no sentido de contribuir com o estudo do tema em termos de seus fundamentos (Moran, 2009).

Ao mesmo tempo, reconhecemos com Taylor (1991/2011) que o tema da autenticidade aparece no bojo das discussões contemporâneas a respeito do self como um de seus constituintes de central importância (Marcon \& Furlan, 2020). Assim, dentre as questões subjacentes à problemática mais ampla do self, entendemos que a autenticidade se apresenta como privilegiada para nossa discussão, na medida em que o tema redobra as tensões epistemológicas acerca do self em um âmbito ético, no qual se expressam de forma patente as 
dimensões concretas de conceitos fundamentais como identidade, singularidade e relacionabilidade.

Em síntese, nossa proposta é realizar uma interrogação introdutória dos fundamentos do problema da autenticidade do si como questão ético-epistemológica, reconhecendo que ela ultrapassa a discussão acerca da fidedignidade de determinada conceituação psicológica (o que um aporte psicológico pode afirmar de autêntico a respeito de uma psique), e passa a se referir também à possibilidade de autocompreensão dessa psique (o que define o agir, relacionar-se ou ser de forma autêntica em relação àquilo que se compreende que se é). Defenderemos que uma leitura deste campo dilemático sob a lente merleau-pontyana possibilita um movimento de rearticulação que vai ao seu encontro em sua aparição mais originária, fenomenologicamente enigmática.

\section{As Tensões do Conceito de Self: Diferentes Compreensões do Si}

A necessidade de uma taxonomia unificada para o campo de problemas relativos ao self pode ser considerada ponto pacífico entre as áreas do saber que o interpelam (Zahavi, 2003). Diferentes correntes do pensamento psicológico enfatizaram e se interessaram por aspectos diversos das problemáticas relativas ao self, dando origem a uma profusão de sentidos múltiplos construídos sob a homofonia do termo (Guanaes \& Japur, 2003; Macedo \& Silveira, 2012). Dado que resgatar com mínima profundidade tais significações exatas exigiria um trabalho revisional historiográfico cuidadoso para cada uma dessas matrizes, sob nosso presente escopo pretendemos visar especificamente as tensões internas presentes no histórico das definições a respeito da noção de self. Portanto, nossa intenção é tomar o self não como conceito definido dentro de qualquer terminologia específica, mas antes e somente enquanto operador teórico de um princípio descritivo a respeito da unidade da experiência individual.

Bamberg e Zielke (2007) estruturam três eixos norteadores em torno dos quais os dilemas centrais que envolvem o conceito se organizam: (1) a questão identitária da constância, (2) a questão identitária da individualidade e (3) a questão estrutural da dinâmica entre sujeito e mundo em sua constituição mútua. Em consonância com Macedo e Silveira (2012), compreendemos que tal classificação nos oferece um panorama com amplitude e precisão suficientes para pensarmos o estado contemporâneo da discussão na ciência

psicológica de forma transversal. Assim, baseados nessa proposta, procuraremos delimitar o campo de questões-limite que perpassam os diferentes construtos a respeito do self para importá-lo em nosso diálogo com a fenomenologia. 
O primeiro dilema - eixo (1) - se refere a uma tensão entre os polos da constância e da mudança, e diz respeito à necessidade de identificação de um caráter de permanência em meio a processos de desenvolvimento e transformação contínua. Ou seja, ao mesmo tempo em que o self muitas vezes é abordado enquanto estrutura (e, neste sentido, persistente no tempo), a descrição de sua atividade frequentemente evoca um caráter processual de flexibilidade e mutabilidade contínua, relativizando a possibilidade mesma de circunscrevê-lo em estruturas estáveis compreensíveis fora de seu contexto efetivo de manifestação - o qual podemos abordar tanto sob o enfoque da vivência individual quanto situados no caráter relacional que ela necessariamente evoca. Em síntese, é possível abarcar o caráter inegável de abertura radical e constante à transformação do self sem se perder o ancoramento de uma igualmente impositiva unidade embasadora que organize e unifique tais processos?

O segundo dilema - eixo (2) - diz respeito às tensões entre a particularidade e a universalidade. Conceptualizar ou descrever os modos de ser si mesmo, seja no âmbito das ciências seja no da filosofia, é uma tarefa que tende a intentar, em alguma medida, um caráter de universalidade. Porém, assim como a natureza processual e transformativa emerge da tentativa de descrever o imobilizado e constante, de forma semelhante o estudo que visa o universal acaba muitas vezes apontando para o particular e o individual como características prementes do campo fenomênico da subjetivação. Dito de outra forma, ao tentar descrever o que há de comum na experiência humana, muito frequentemente o que se apresenta é o caráter sui generis dos processos de individuação, os quais apontam para maneiras indefinidamente múltiplas de constituição do self e, ao fazê-lo, podem lançar dúvidas sobre as próprias tentativas de conceituação universal de onde tais reflexões partiram - ou as quais no mínimo tangenciaram - em sua tentativa de circunscrever o fenômeno. Em síntese, é possível uma compreensão que abarque o caráter particularizante do self sem abrir mão de uma visão teórica abrangente e em alguma medida categorizante, isto é, que não se recolha a uma metodologia da pura narrativa casuística?

Por sua vez, o terceiro dilema - eixo (3) - diz respeito ao estatuto dos processos de significação emergentes da interação entre pessoa e mundo. Com a tendência a se postular duas direções possíveis para o ajustamento dessa dinâmica advém uma tensão entre compreender tal processo como regido primordialmente pelo ajustamento da pessoa ao mundo ou de um ajustamento do mundo à pessoa. Mais um problema de direção de movimento do que de polarização excludente, trata-se de uma escolha entre compreender o desenvolvimento do self primordialmente no sentido pessoa-mundo ou no sentido mundo-pessoa. Em síntese, a ênfase mais esclarecedora sobre os processos de subjetivação se encontra no indivíduo como 
responsivo a configurações ambientais que precedem e ultrapassam sua experiência particular, ou em seu poder expressivo individual ou relacional de significar e ressignificar a própria experiência de mundo?

Compreendemos que as ênfases variadas com que o tema geral do self foi adereçado nas diferentes escolas de pensamento refletem alternativas da tentativa de resposta a essas questões, ou seja, de lidar com tais tensões de forma abrangente. A herança teórica e filosófica na qual se embasa determinada corrente de pensamento e o contexto prático em meio ao qual ela surge e se desenvolve influenciam a forma com que a questão se apresenta aos seus estudiosos, o que tradicionalmente envolveu a postulação de um dos termos das correlações como sendo o primordial à análise.

Mais do que retraçar as origens de tais concepções, nos interessa especificamente notar o seguinte: é justamente ao terreno filosófico que o psicólogo se encontra remetido quando se depara com essas configurações dilemáticas que tracejam uma fronteira de questões-limite comum à investigação psicológica em toda sua variedade. Oferecendo a possibilidade nos conduzir ao campo comum que se encontra ao fundo de tais formulações, a fenomenologia nos parece particularmente bem posicionada para encaminhá-las de forma promissora.

\section{Husserl, Heidegger e Sartre: o Self como Experiência e a Questão da Autenticidade}

A apreensão do pensamento fenomenológico pela psicologia se deu a partir de frentes diversas, o que remonta em parte ao duplo sentido do movimento husserliano inaugurador, cujo cerne consiste em estabelecer um saber (uma ciência, no sentido ampliado de Wissenschaft) rigoroso acerca dos fenômenos, o qual deve ser compreendido como fundamental em relação a todo saber possível acerca de quaisquer objetividades. Sob a investigação fenomenológica, o fator subjetivo encontra-se radicalmente recolocado em concomitância com o objetivo - a diferenciação (ou não) entre estes polos correlativos sendo revisitada e retrabalhada sem nunca deixar de ocupar lugar de destaque (Barbaras, 2011).

Aparentada tanto à psicologia quanto à lógica, a filosofia husserliana se propõe como uma crítica simultânea aos pressupostos dominantes tanto na filosofia neokantiana quanto às posturas psicologistas que ganhavam força na passagem ao século XX. Rejeitando todo tipo de psicologismo, mas também o logicismo matemático e o neocriticismo de viés idealista, Husserl identifica a descrição rigorosa da experiência como ponto de partida necessário para seu movimento de fundamentação, o qual visa a superação dos contrassensos produzidos 
nesse campo de cisão entre concepções realistas e idealistas. Esse retorno à experiência propriamente dita significa tanto uma rejeição de quaisquer concepções a respeito de suas fontes quanto um compromisso de rigor a respeito daquilo que se mostra enquanto tal.

Nesse contexto, a perspectiva propriamente psicológica do self localiza-se no panorama de questões apreensíveis de forma análoga por uma psicologia que se queira fenomenológica, porém derivada em relação à empreitada fenomenológica husserliana cujo interesse se volta a um movimento de refundação mais profundo e geral dos saberes. Ou seja, interessa centralmente ao autor o desvelamento do "eu puro" (Husserl, 1913/2018, p. 132) ou "eu transcendental" (Husserl, 1931/2013, p. 62), o qual figura como "resíduo" da redução fenomenológica primariamente como polo necessário de direcionalidade que perpassa os vividos, um componente imanente básico da experiência que não equivale à acepção do "eu psicológico" (Husserl, 1931/2013, p. 62).

Entretanto, o desenvolvimento da fenomenologia inaugural não deixou de conduzir o filósofo à tematização direta da concretude da experiência de si, onde o eu transcendental não se esquiva de aparecer como momento de uma concretude sempre pessoalizada e, assim, passível de ser investigada por uma disciplina psicológica descritiva de caráter fundamental, ou seja, construída sobre as bases fenomenológicas. Assim é que encontramos em Husserl (1931/2013, p. 104) a diferenciação entre o ego tomado como "polo idêntico de vivências" e como "substrato de habitualidades". Através dessa confluência de sentidos, o autor assinala a inadequação de se assumir o ego como um "polo de identidade vazio", já que "o próprio ego é para si próprio um ser numa evidência contínua, portanto, a si em si mesmo continuamente se constituindo enquanto ser" (Husserl, 1931/2013, p. 104, grifo original do autor). O ego transcendental tem a si mesmo primariamente sob a forma de uma autoconstituição - a qual se diferencia, por definição formal, da constituição de todo transcendente. Toda autocompreensão do self se mostraria aí, portanto, fundada em uma doação originária de si a si, a qual deve ser precisada por meio da descrição fenomenológica, por suas diferentes vias possíveis.

Já a fenomenologia de Heidegger desenvolve a busca pelo originário fundante no sentido de adereçar a questão a respeito do ser, a qual considera ter sido negligenciada no desenvolvimento histórico das tradições filosóficas ocidentais. Com isso, efetua o que poderia se chamar de virada existencial sobre o campo husserliano, deslocando o foco da apreensão reflexiva do ser presumido como dado nas aparições (fenômenos) para a compreensão das aparições como modos de apresentação de um ser (existência) que as estrutura e precede e 
que, por conta disso, convoca uma ontologia capaz de elucidá-lo anteriormente a toda tarefa lógico-reflexiva.

O Dasein, termo que designa o ente que se interroga a respeito do ser - o homem enquanto existência -, caracteriza-se na leitura heideggeriana por sua indeterminação radical ${ }^{3}$, ou seja, pelo caráter de abertura (Erschlossenheit) ou de projeto de um ser que, sendo, colocase em jogo. Um dos ganhos deste ponto de vista remete à possibilidade de apreender o ser a partir de sua aparição primária efetiva, o que envolve apreendê-lo em sua lida cotidiana com o mundo a partir da qual emergem suas compreensões a respeito daquilo que é, dispensando a recorrência a qualquer teoria prévia da subjetividade que a fundamentasse.

Ou seja, ao invés de partir da relação específica entre consciência cognoscente e objeto conhecido, a analítica heideggeriana se inicia discorrendo sobre o Dasein em sua atividade cotidiana, campo a partir do qual emergem todas as compreensões possíveis a respeito de tudo aquilo que é, incluindo aí as (auto)compreensões do Dasein, científicas ou não, a respeito do que constitui um self ou das prerrogativas éticas do agir em autenticidade. Assim, somos conduzidos da autoconstituição de um ego polarizado pela reflexividade à autocompreensão de um ser-no-mundo cujos atos de significação emergem sempre de uma co-abertura entre ser e mundo que aparece primariamente através de uma lida originária e prática.

Como parte de seu itinerário filosófico em Ser e Tempo (1927), ao se deter sobre a tarefa que definiu como uma analítica do Dasein, Heidegger (1927/2012) postula uma distinção entre os modos-de-ser próprio (Eigentlich, por vezes traduzido como autêntico) e impróprio (Uneigentlich, por vezes traduzido como inautêntico). Complementarmente à noção de uma existência que precede ontologicamente toda essência predicável a seu respeito, o autor apresenta as noções de propriedade (Eigentlichkeit, por vezes traduzido como autenticidade) e de impropriedade (Uneigentlichkeit, por vezes traduzido como inautenticidade) como descritivas de seu caráter ético de ser-cada-vez-meu:

O Dasein é, cada vez, sua possibilidade e ele não a "tem" somente como propriedade de um subsistente. E, porque o Dasein é, cada vez, essencialmente sua possibilidade, esse ente em seu ser pode se "escolher", pode ganhar a si mesmo ou pode se perder, isto é, nunca se ganhando ou só se ganhando "em aparência". Ele só pode se haver perdido ou ainda não ter se ganhado na medida em que, segundo sua essência, é um possível ser próprio, isto é, na medida em que ele tem a possibilidade de se apropriar de si. Os dois modi-de-ser da propriedade e da impropriedade - expressões terminológicas escolhidas no estrito sentido da palavra - fundam-se em que o Dasein é 
em geral determinado pelo ser-cada-vez-meu. (Heidegger, 1927/2012, pp. 141, grifos originais do autor)

Sob a forma da cotidianidade, o encontrar-se (Befindlichkeit) do Dasein não se dá no mais das vezes como incerteza absoluta, como constante reconhecimento desse seu ter-de-ser originário. Pelo contrário, no modus cotidiano de ser o que se observa é um caráter de articulação entre o projeto de ser e o seu aí, que se dá segundo formas de compreensão que modulam a experiência humana de mundo, enquanto ser lançado. Absorvido em sua lida cotidiana com o mundo, o Dasein não age no mais das vezes no sentido de se apropriar autenticamente de si, mas sim na lida constante com as solicitações do mundo. Sua doação a si se dá sempre no contexto prático-utilitário de um mundo no qual o sentido dos atos pessoais encontra-se já dado, sob estratificações diferentes, nas estruturas de um mundo-ambiente (Umwelt) e sob os modos originários do ser-com (Mitsein).

É justamente se inserindo neste entendimento que se torna possível ao Dasein se ganhar em aparência, um modo de realização do si mesmo que, por definição (enquanto experimentado como efetiva realização), dissimula-se em relação ao seu próprio caráter de possibilidade e indefinição radical. Se existe aqui uma tensão entre o individual e o campo comunitário de sentidos, realçada pela escolha terminológica do decair e da impropriedade (a qual deve ser pormenorizada em uma análise mais cuidadosa), é bastante claro já de início na análise heideggeriana o quanto a questão não remete a uma simples polarização, já que toda a existência - seja ela vivida no modo da propriedade ou da impropriedade - se dá na vivência efetiva de horizontes de mundo vivido, no ser-aí lançado ao seu mundo:

Impróprio e não-próprio de modo algum significa "propriamente não", como se com esse modus-de-ser o Dasein perdesse em geral o seu ser. Impropriedade não significa algo semelhante a já-não-ser-no-mundo, pois constitui precisamente o contrário, a saber, um assinalado ser-no-mundo completamente tomado pelo "mundo" e pelo Dasein-com com os outros em a-gente. O não-ser-si-mesmo tem a função de uma possibilidade positiva do ente que, essencialmente ocupado, é absorvido em um mundo. Esse não-ser deve ser concebido como o imediato modo-de-ser em que no mais das vezes o Dasein se mantém. (Heidegger, 1927/2012, pp. 493)

Na cotidianidade, o Dasein se apoia sobre as compreensões intramundanas no entendimento não apenas do mundo, mas também do próprio si, de modo que esse não-ser-si- 
mesmo caracteriza uma interpretação impessoal do próprio ser-no-mundo, que se apresenta assim como uma autocompreensão inautêntica. A inautenticidade possui, desta forma, um caráter de dispersão do si no impessoal. A experiência que salvaguarda o si dessa dispersão e aponta para o sentido da totalidade originária do Dasein é a angústia (Angst), sentimento caracterizado pela revelação, em recuo e isolamento em relação à compreensão cotidiana (ao sentido naturalizado das coisas e de toda a experiência), da propriedade do ser-aí enquanto preocupação ou cura (Sorge). É somente a partir dessa radical apropriação angustiada que o ser-aí se singulariza, compreendendo-se resolutamente em seu caráter mais próprio (autêntico) de possibilidade.

Em continuidade crítica com a ontologia heideggeriana, o pensamento fenomenológico de Sartre, ao contrário da primeira, não dispensa o recurso a uma filosofia da consciência como meio legítimo de compreensão do campo existencial. Enfatizando o caráter reflexivo da experiência do si mesmo, Sartre apresenta em O Ser e o Nada (1943) um panorama de contraposição entre os modos inteiramente diferentes do ser-para-si e do ser-emsi. Essa separação reedita e aprofunda a crítica sartreana ao conceito husserliano de ego, baseada no reconhecimento do caráter necessariamente transcendente do ego (poderíamos dizer, de toda propriedade identitária do self) em relação à experiência de ser consciência propriamente dita.

Sartre (1943/2005) radicaliza os caráteres de projeto e escolha do ser para-si, enraizando-os em uma compreensão da consciência como negatividade. A constitutiva negatividade ${ }^{4}$ (a nadidade) do ser-para-si (ser da consciência apreendido experiencialmente) postula sua radical separação em relação ao ser-em-si (ser das coisas, à semelhança do qual o ser da consciência de outrem aparece), de forma que seu caráter de constante transcendência temporal o situa como projeto sempre fracassado, uma vez que seu ser, sempre desejoso de ser, por mais que componha com o mundo e com outrem, jamais se positiva como ser em-si (ou seja, estritamente como sendo), permanecendo portanto melhor descrito como não-ser. $\mathrm{Ou}$ seja, a questão da propriedade deixa de ser a respeito da possibilidade de se ganhar ou se perder, o inautêntico deixa de poder ser uma possibilidade positiva já que o ser-para-si, por definição, já não é.

Dentre as diversas atitudes da existência humana que podem ser usadas para ilustrar sua posição como origem articuladora de toda negatividade, a má-fé (mauvaise foi) se apresenta como privilegiada no itinerário sartreano. É para esse campo de atitudes que o autor se dirige imediatamente após postular o primado da negatividade, justamente porque a má-fé articula o caráter "metaestável", ambivalente, da concretude humana enquanto simultâneo de 
“transcendência-facticidade", simultâneo ser-para-si e ser-para-outro (Sartre, 1943/2005 p. 104).

É no âmbito da assunção do próprio caráter como liberdade de escolha que reside a distinção entre o modo de ser autêntico, que não se dissimula em relação à própria condição concreta (de ser experiência de negatividade-facticidade em meio à plenitude do ser) e a máfé, modo de ser inautêntico em que o para-si dissimula-se como se fosse em-si (o que vale também no sentido oposto), atribuindo a si mesmo predicados cuja falsidade o próprio poder fazê-lo já revela por definição - "empastando (a transcendência) com toda a facticidade do presente, (...) [a má-fé atua como um] transcender coagulado que já não transcende para nada" (Sartre, $1943 / 2005$ p. 104).

Esperamos que esses breves posicionamentos não apenas situem o trabalho de Merleau-Ponty em relação a três de suas principais influências nesse campo de questões, mas também ilustrem o sentido no qual essas compreensões fenomenológicas, reconhecidamente distintas entre si, mantêm em comum o privilégio de se pensar a autenticidade do self como articulada intimamente à sua possibilidade absoluta de recuo: seja em termos-limite da existência lançada, na angústia heideggeriana que faz recuar o sentido cotidiano de mundo; seja descrito como aquilo que caracteriza a própria transcendência do si, na negatividade definidora da consciência sartreana. Em ambos os casos, toda e qualquer predicação do self, compreendido como ser de possibilidade, remete à própria experiência singularizante desse ser-possibilidade como critério necessário (ainda que não suficiente) para ser compreendido autenticamente enquanto tal.

Conservam-se, de certa maneira, os caráteres dilemáticos de nossos eixos tensionais: constância e mudança, particularidade e universal, pessoa e mundo podem ser situados como polarizações descritivas de uma existência de certa forma cindida, cuja propriedade tende, em última instância, a escapar a si mesma sob a forma da dispersão ou da má-fé, e toda salvaguarda contra isso depende da possibilidade individual de se assumir autenticamente como possibilidade situada em tais eixos.

\section{Autenticidade em Merleau-Ponty: o Self Encarnado}

Ao postular-se a alternativa tensional entre experiências de self autênticas e inautênticas, os dilemas do conceito são retomados sob um novo prisma, o qual se revela crucial para a sua própria definição. Podemos nos indagar de que maneira se articulam a respeito da autenticidade as antípodas conceituais do eixo 1, constância e mutabilidade (A 
experiência autêntica tende a se organizar sempre em torno de uma mesma essência ou sua característica central é a constante mudança e transformação?); do eixo 2, unicidade e universalidade (De que forma se dá o caráter singularizante da individuação? Em que medida ele evoca a necessidade de originalidade e/ou expressão criativa, em oposição a um campo de sentidos socialmente compartilhado?) e do eixo 3, do sentido primordial da dinâmica de tais processos na relação entre indivíduo e mundo (Quais são os modos pelos quais a tensão entre tais polos se faz presente no decorrer desse processo? De que forma se dá a dinâmica entre liberdade e situação na organização da possibilidade de vivências autênticas?).

Seja no extensivo projeto fenomenológico de Husserl, na analítica do Dasein de Heidegger ou na ontologia fenomenológica de Sartre, tais questionamentos se articulam com o enfoque de uma noção descritiva da experiência vivida de mundo, sendo que são profícuos e extensivos os diálogos de tais obras com a teoria e prática psicológicas atuais, no que tange ao trato dessas questões. Menos evocados neste âmbito são os desdobramentos e consequências do pensamento de Merleau-Ponty no que se refere especificamente à problemática da autenticidade.

Uma das vantagens de se abordar este campo temático a partir da perspectiva merleaupontyana nos parece ser a maneira com que ela tende a adereçar questões de natureza dicotômica. O aporte do autor a problemas que se apresentam como tensionamentos radicalmente polarizados tende a ser o da investigação das raízes comuns que se encontram sob soluções teóricas aparentemente inconciliáveis. Uma vez situado nesse nível comum da experiência, onde espera-se que as tradições antagonistas se revelem originariamente (préreflexivamente) niveladas, torna-se possível reabilitar a compreensão da própria ambiguidade como elemento constitutivo da experiência enquanto tal - uma boa ambiguidade nãoparadoxal, um sentido de equivocidade que não implica necessariamente em contrassenso. Trata-se, conforme antevimos, de um movimento tipicamente fenomenológico no qual o autor propõe, sob uma atitude rigorosa de recuo, um retorno à própria experiência (originária e préreflexiva), visando com isso desvelar a cooriginariedade concreta de âmbitos que foram tradicionalmente separados pela própria reflexão.

Conforme sintetiza Villela-Petit (2008), Heidegger rejeita por inteiro o movimento cartesiano decisivo (penso, logo existo), evocando o que identifica como uma má asserção ontológica do modo de ser do eu penso, da carência de uma elucidação hermenêutica do existo, propondo a recolocação de toda a problemática a partir de um ponto de partida radicalmente diverso, que acaba por subsumir o ser da consciência à concretude primeira do Dasein. Em maior proximidade com o Husserl posterior, Merleau-Ponty busca realizar uma 
retomada efetiva da questão cartesiana e explorá-la no campo de problemas que ela própria faz abrir. Assim, o autor propõe uma superação interna da dicotomia cartesiana, identificando a problemática fenomenológica não na falta de elucidação hermenêutica a respeito do sentido do existo, mas antes pelo cair na armadilha da reflexão, resultando na identificação do cogito com um espírito puro que seria para si necessária e suficientemente tão logo fosse pensante, e em relação ao qual o mundo não seria senão, por definição, o conjunto de ideias ou cogitatia presentes ou possíveis (Villela-Petit, 2008).

Ou seja, ao contrário de Heidegger e em maior proximidade com Sartre, o aporte merleau-pontyano não se furta a aproximar a tematização do campo existencial de uma filosofia da consciência - mais especificamente, sob a forma um projeto de radical recolocação da mesma. Trata-se de compreender a consciência remetendo-a a sua experiência efetiva e original de mundo, a qual o autor situa no campo perceptivo. Antecedendo os âmbitos da reflexão e do entendimento, a abertura perceptiva aparece em Fenomenologia da Percepção (Merleau-Ponty, 1945) como terreno privilegiado para se compreender a experiência do si mesmo e de seus modos de existência.

O corpo percipiente, compreendido como corpo próprio (corps propre), adquire um papel central para tal empreitada na medida em que apresenta um campo de questões fundamentais que resiste aos enquadramentos dualistas no mesmo movimento em que aponta para compreensões renovadas - o qual, afinal de contas, evoca a ideia do ambíguo e do equívoco como elementos constitutivos da experiência humana, um dado fenomenológico que uma descrição consequente da atividade perceptiva não deve ignorar:

A experiência do corpo próprio (...) revela-nos um modo de existência ambíguo. Se tento pensá-lo como um conjunto de processos em terceira pessoa - "visão", "motricidade", "sexualidade" - percebo que essas "funções" não podem estar ligadas entre si e ao mundo exterior por relações de causalidade, todas elas estão confusamente retomadas e implicadas em um drama único. Portanto, o corpo não é um objeto. Pela mesma razão, a consciência que tenho dele não é um pensamento, quer dizer, não posso decompô-lo e recompô-lo para formar dele uma ideia clara. Sua unidade é sempre implícita e confusa. Ele é sempre outra coisa que aquilo que ele é, sempre sexualidade ao mesmo tempo que liberdade, enraizado na natureza no próprio momento em que se transforma pela cultura, nunca fechado em si mesmo e nunca ultrapassado. (...) Portanto, sou meu corpo, exatamente na medida em que tenho um saber adquirido e, reciprocamente, meu corpo é como um sujeito natural, como um 
esboço provisório de meu ser total. Assim, a experiência do corpo próprio opõe-se ao movimento reflexivo que destaca o objeto do sujeito e o sujeito do objeto, e que nos dá apenas o pensamento do corpo ou o corpo em ideia, e não a experiência do corpo ou o corpo em realidade. (Merleau-Ponty, 1945/2006, pp. 269, grifo nosso)

Enraizar a compreensão da problemática da autenticidade (e, com ela, do próprio self) no campo perceptivo evoca a necessidade de uma investigação a respeito desse modo de existência fundamentalmente ambíguo entre ser de possibilidades e possibilidades de ser. Por outro lado, reconhecer o corpo próprio como nunca fechado em si mesmo e nunca ultrapassado também relativiza as certezas (e, portanto, o caráter de autenticidade) possíveis a respeito de quaisquer de seus momentos (auto)compreensivos, já que esse campo originário não é apenas fundante, mas mantém-se em continuidade necessária como campo fundado de sentidos, uma vez que toda a atividade reflexiva se dá na espessura de uma inserção sensível no mundo.

A corporeidade surge, portanto, como o ponto nodal onde se encontram articulados de forma estreita, na experiência pré-reflexiva, esses termos polarizados que a atividade reflexiva nos oferece. Enquanto armação primordial de possibilidades de ser, o corpo próprio é o efetivo ser de possibilidades. A corporeidade, termo último da redução merleau-pontyana, não se apresenta como conjunto de propriedades delimitadas, mas antes como campo onde toda propriedade pode ser articulada a partir de uma abertura (o que, portanto, requer que nenhuma delimitação seja definitiva). Toda atividade (auto)compreensiva, uma vez enraizada no corpo, revela um caráter perceptivo que precede (funda, portanto, excede) o que tradicionalmente se atribui ao pensamento judicativo, que consiste na delimitação precisa daquilo que é, tanto quanto daquilo que sou e/ou posso vir a ser.

Tomado a partir de sua corporeidade, o caráter reflexivo do self acaba restituído de sua dimensão inescapavelmente experiencial: o si mesmo não possui primariamente uma identidade fechada enquanto conjunto ideativo sobre si, enquanto tese a respeito de seu próprio ser, nem mesmo a partir da intuição, sempre possível, de sua própria condição de radical possibilidade. Na proposta merleau-pontyana, a consciência de si é dada na própria evidência perceptiva, porém não como contato absoluto de si consigo, dispensando a necessidade de se refundar essa autorreferencialidade como nada além de parte da própria estrutura da abertura ao mundo (ambígua e inultrapassável) efetivada pela percepção: 
Não precisamos perguntar-nos porque o sujeito pensante ou a consciência se apercebe como homem ou como sujeito encarnado ou como sujeito histórico, e não devemos tratar esta apercepção como uma operação segunda que ele efetuaria a partir de sua existência absoluta: o fluxo absoluto se perfila sob seu próprio olhar como "uma consciência" ou como homem ou como sujeito encarnado porque ele é um campo de presença - presença a si, presença a outrem e ao mundo - e porque esta presença o lança no mundo natural e cultural a partir do qual ele se compreende. Não devemos representá-lo como contato absoluto consigo, como uma densidade absoluta sem nenhuma fenda interna, mas ao contrário como um ser que se prossegue no exterior. (Merleau-Ponty, 1945/2006, pp. 605)

Notemos que, no mesmo movimento em que recusa a tese de um contato absoluto consigo, Merleau-Ponty encaminha a problemática no sentido da compreensão de um ser que se prossegue no exterior. O caráter reflexivo da presença assim descrita acaba evocando, no âmago da singularidade, a espessura da experiência mundana: enquanto abertura, o si está em contato consigo necessariamente através de sua experiência sensível efetiva. $\mathrm{O}$ si é desde sempre experiência sensível (ambígua e inultrapassável) de mundo, já que, enquanto abertura, se insere e retoma ativamente situações sempre inacabadas, tendo a si mesmo situado na própria evidência experiencial deste contato, um aparecer que percorre sua co-abertura de mundo (prosseguindo-se no exterior) antes que possa ter a si mesma como campo de presença dele discernível.

Enquanto é certo que o Dasein de Heidegger também se defina como presença a si, a outrem e ao mundo no modo de uma co-abertura originária, o estatuto dessa presença encontra-se radicalmente recolocado em Merleau-Ponty. Com isso, o caráter de projeto do si mesmo se apresenta sob uma nova luz. Em Heidegger, o âmbito da ação do si mesmo autêntico evoca uma relação específica com o tempo, o sentido do porvir e a finitude. A separação fundamental postulada entre o próprio e o impróprio (autêntico e inautêntico) embasa uma compreensão do existente como "ser-resoluto precursor" (Heidegger, 1927/2012, p. 887-889), e, se o autor afirma que "a temporalidade descobre-se como o sentido da preocupação própria", é no contexto de reconhecer que sua compreensão autêntica de si depende dessa antecipação de si mesmo no futuro, o que consequentemente delineia um fluxo que advém do próprio futuro.

Conforme indica Villela-Petit (2008), trata-se de pormenorizar a diferença entre a vista (Sicht) existencial heideggeriana e o seu equivalente no contexto do pensamento de Merleau- 
Ponty, fundado radicalmente na experiência perceptiva. A primeira é um olhar sempre em vias de se metaforizar, na medida em que se articula a uma possibilidade de ser próprio que se dá no âmbito de um projeto, uma espontaneidade da decisão resoluta, uma antecipação que toma como necessário um recuo em relação ao efetivo agora situacional para se perceber em situação. A segunda, por sua vez, nos reenviando à espessura do presente e, reinserindo o fluxo temporal como fundamento da espontaneidade (e não o contrário), procura situar um existente que é sempre na plenitude sensível do mundo, em continuidade e contato consigo, com outrem e com o mundo.

A alternativa entre ser de possibilidades (ontológico) e ser de propriedades (ôntico) postula que a única propriedade (no sentido lato como característica, mas também no sentido estrito como autenticidade) possível ao Dasein se encontra no compreender-se como possibilidade de forma resoluta. Em Heidegger, isso nos conduz para a tese de uma existência absoluta que, em posse de si mesma enquanto projeto, se presentiza sempre em relação a um futuro. Merleau-Ponty, por sua vez, concederá primazia à própria experiência presente, enfatizando a facticidade ambígua e inescapável do sensível como contestadora da possibilidade de se conceptualizar esse si absoluto:

O tempo histórico de Heidegger, que flui do porvir e que, pela decisão resoluta, antecipadamente tem seu porvir e salva-se de uma vez por todas da dispersão, é impossível segundo o próprio pensamento de Heidegger: pois, se o tempo é um ekstase, se presente e passado são dois resultados desse êxtase, como deixaríamos totalmente de ver o tempo do ponto de vista do presente, e como sairíamos definitivamente do inautêntico? É sempre no presente que estamos centrados, é dele que partem nossas decisões; portanto, elas sempre podem ser postas em relação com nosso passado, nunca são sem motivo e, se elas abrem em nossa vida um ciclo que pode ser inteiramente novo, devem ser retomadas na sequência, elas só nos salvam da dispersão por certo tempo. Portanto, não se pode tratar de deduzir o tempo da espontaneidade. Nós não somos temporais porque somos espontâneos e porque, enquanto consciências, nos afastamos de nós mesmos, mas ao contrário o tempo é o fundamento e a medida de nossa espontaneidade, a potência de ir além e de "niilizar" que nos habita, que nós mesmos somos, ela mesma nos é dada com a temporalidade e com a vida. (Merleau-Ponty, 1945/2006, pp. 573) 
Em contraposição à niilização sartreana, que entende o caráter de constante transcendência da consciência como componente ontológico de radical diferenciação entre ser puramente para-si e ser puramente em-si, a potência de niilização do corpo próprio merleaupontyano aparece situada na continuidade e espessura de uma experiência dada com a temporalidade e com a vida. Em contraposição a um sujeito heideggeriano, que experiencia em última instância a própria liberdade como possibilidade radical de preocupação própria, a temporalidade merleau-pontyana aparece como fundadora de toda espontaneidade, identificada à própria atividade subjetiva que é sempre inescapavelmente inscrita na continuidade do sensível. Evitando as vias compreensivas que subentendem uma possibilidade radical de recuo, a compreensão merleau-pontyana nos encaminha, portanto, em direção a um sujeito que se conhece e experiencia a si mesmo autenticamente enquanto possibilidade sempre em sua pertença efetiva, ou seja, enquanto inerência radical de contato.

Essa via compreensiva nos sinaliza a possibilidade de conceitualizar, sem cair em contradição, sobre o que há de concretude no indeterminado (eixo 1), de universal na singularização (eixo 2) e de passividade na liberdade (eixo 3) - e vice-versa, para todos os casos. A perspectiva merleau-pontyana abre uma rota possível para tanto na medida em que questiona o caráter absoluto de quaisquer destas polaridades, seus termos sendo recolocados em relação a um campo de experiência que se revela tanto ambíguo quanto não-ultrapassável. Desdobramento razoável para qualquer investigação que se volte para fundamentos, a tradicional postulação de absolutos é colocada em xeque quando a experiência do ser de compreensão (e sua correlativa compreensão de ser) se revela, via fenomenologia da experiência perceptiva, estruturada por uma corporeidade inegavelmente ambígua, cuja regulagem de sentidos se dá aquém das categorias já refletidas - idealmente purificadas de toda equivocidade - com as quais tentamos enquadrá-la.

Esforços futuros em aprofundar as problemáticas da autenticidade e do self à luz do pensamento merleau-pontyano devem passar, portanto, por investigações pormenorizadas da articulação entre o campo de problemas do si e o desenvolvimento das compreensões e propostas do autor a respeito da elucidação filosófica desse contato originário espontâneo, em suas diferentes manifestações fenomênicas - as quais, entretanto, remontam para uma mesma totalidade que se compreende, sem possibilidade de recuo último, no próprio contato. 


\section{Referências}

Bamberg, M., \& Zielke, B. (2007). From dialogical practices to polyphonic thought? Developmental inquiry and where to look for it. International Journal for Dialogical Sciences, 223-242. 223 de http://ijds.lemoyne.edu/journal/2_1/index.html

Barbaras, R. (2011). Investigações fenomenológicas: Em direção a uma fenomenologia da vida. Curitiba: UFPR

Guanaes, C., \& Japur, M. (2003). Construcionismo social e metapsicologia: Um diálogo sobre o conceito de self. Psicologia: Teoria e Pesquisa, 19(2), 135-143. doi:10.1590/S010237722003000200005

Heidegger, M. (2012). Ser e tempo (F. Castilho, Trad.). Petrópolis: Vozes. (Obra original publicada em 1927)

Husserl, E. (2018). Ideias para uma Fenomenologia Pura e para uma filosofia fenomenológica: Introdução geral à fenomenologia pura (Márcio Suzuki, Trad.). Aparecida, SP: Ideias \& Letras. (Obra original publicada em 1913)

Husserl, E. (2013). Meditações Cartesianas e Conferências de Paris (Pedro M. S. Alves, Trad.). Rio de Janeiro: Forense. (Obra original publicada em 1931)

Macedo, L. S. R., \& Silveira, A. C. (2012). Self: A concept in development. Paidéia (Ribeirão Preto), 22(52), 281-290. doi:10.1590/S0103-863X2012000200014

Marcon, G., \& Furlan, R. (2020). A questão identitária na pós-modernidade: Autenticidade e individualismo em Charles Taylor. Psicologia USP, 31, 1-10. doi:10.1590/0103$6564 \mathrm{e} 190048$

Merleau-Ponty, M. (2006). Fenomenologia da Percepção (C. A. R. Moura, Trad.). São Paulo: Martins Fontes. (Obra original publicada em 1945)

Moran, D. (2009). The Phenomenology of Personhood: Charles Taylor and Edmund Husserl. FEU Colloquium, 3(1). 80-104. Recuperado de https://ejournals.ph/article.php?id=1950

Sartre, J.-P. (2005). O Ser e o nada: Ensaio de ontologia fenomenológica. Petrópolis: Vozes. (Obra originalmente publicada em 1943)

Spink, M. J. P. (2011). Pessoa, indivíduo e sujeito: Notas sobre efeitos discursivos de opções conceituais. In M. J. P. Spink, P. Figueiredo, \& J. Brasilino (Orgs.), Psicologia social e pessoalidade (pp. 1-22). Rio de Janeiro: Centro Edelstein de Pesquisas Sociais, ABRAPSO. 
Taylor, C. (2011). A ética da autenticidade (T. Carvalho, Trad.). São Paulo, SP: É Realizações. (Obra original publicada em 1991)

Villela-Petit, M. (2008). Le soi incarné: Merleau-Ponty et la question du sujet. In SaintAubert (Org.), Maurice Merleau-Ponty. Sous la direction d'Emmanuel de Saint Aubert (pp. 79-123). Paris: Hermann.

Zahavi, D. (2003). "Phenomenology of Self." In T. Kircher \& A. David (Eds.), The Self in Neuroscience and Psychiatry (pp. 56-75). Cambridge: Cambridge University Press.

\section{Endereço para correspondência}

\section{Gilberto Hoffmann Marcon}

Universidade de São Paulo

Faculdade de Filosofia, Ciências e Letras de Ribeirão Preto - Departamento de Psicologia

Avenida Bandeirantes, 3900, Monte Alegre, Ribeirão Preto - SP, Brasil. CEP 14040-901

Endereço eletrônico: ghmarcon@gmail.com

\section{Reinaldo Furlan}

Universidade de São Paulo

Faculdade de Filosofia, Ciências e Letras de Ribeirão Preto - Departamento de Psicologia

Avenida Bandeirantes, 3900, Monte Alegre, Ribeirão Preto - SP, Brasil. CEP 14040-901

Endereço eletrônico: reinaldof@ffclrp.usp.br

Recebido em: 04/07/2020

Aceito em: 04/09/2020

\section{Notas}

* Psicólogo, Mestre em Psicologia e Doutorando em Psicologia pela Universidade de São Paulo - USP, Faculdade de Filosofia, Ciências e Letras de Ribeirão Preto.

** Doutor em Filosofia. Professor Livre-Docente do Departamento de Psicologia da Faculdade de Filosofia, Ciências e Letras de Ribeirão Preto - USP.

${ }^{1}$ Compreendemos que a proximidade terminológica entre tais conceitos é indicativa de um campo comum de questões fenomenológicas mutuamente relacionadas (Moran, 2009). É neste sentido que, ao longo do artigo, utilizamos o termo "pessoa" como concomitante possível ao termo "self", não aludindo à conotação etimologicamente mais rigorosa do termo (que poderia ressaltar o caráter posicional-performático, a partir do latim persona), mas sim à compreensão estritamente experiencial do problema da pessoalidade (personhood), intimamente relacionada à problemática do próprio self (selfhood) (Moran, 2009).

${ }^{2}$ Conforme aponta Spink (2011), o substantivo de origem anglo-saxã possui tanto a vantagem de frisar o aspecto experiencial reflexivo (compartilhada, em parte, no português, pelo "si" substantivado), quanto a de tradicionalmente ressaltar o aspecto relacional enquanto alternativa ao "eu" ("I"), na contraposição à alteridade. 
3 “A 'essência' desse ente reside em seu ter-de-ser. O ser-que (essentia) desse ente, na medida em que em geral disso se pode falar, deve ser concebido a partir do seu ser (existentia)." (Heidegger, 1927/2012, p. 139).

${ }^{4}$ A negação sartreana não corresponde a uma "estrutura da proposição judicativa" meramente enunciada por uma consciência constituinte, mas, antes e mais originariamente, revela-se como estrutura concreta da própria consciência, a qual “origina e fundamenta (toda) negação.” (Sartre, 1943/2005, p. 47)

Financiamento: A pesquisa relatada no manuscrito foi financiada pela bolsa de doutorado do primeiro autor (CAPES, Cota Institucional (Demanda Social), Programa de Pós-Graduação em Psicologia FFCLRP - USP).

Este artigo de revista Estudos e Pesquisas em Psicologia é licenciado sob uma Licença Creative Commons Atribuição-Não Comercial 3.0 Não Adaptada. 